\title{
Pengaruh Penggunaan Smartphone Terhadap Perubahan Perilaku Siswa (Studi Kasus Siswa Sekolah Menengah Atas Negeri 5 Palembang)
}

\author{
M. Mifta Farid, Muhammad Hafidz Al-Furqan \\ Fakultas Ilmu Sosial dan Ilmu Politik Universitas Islam Negeri Raden Fatah Palembang \\ Email: dagucoklat@gmail.com
}

\begin{abstract}
The era of Technology and Information which is now completely practical and fast certainly makes many people want to try to participate in it. Smartphones are smart phones that have evolved to this day become a tool that can be used by many people to not only communicate, but also to entertain themselves, to get information, learn to work and online selling. Smartphones are getting more and more years, so they are growing rapidly, especially to the millennial generation and the current generation $\mathrm{Z}$ is feared to be able to influence changes in their daily behavior. Smartphones that become daily needs for teenagers will certainly be viewed from various sides, whether a big positive and negative affect on the behavior that they apply every day. The number of smartphone users from existing data shows the amount of enthusiasm of teenagers to access the internet through smartphones. This research was made with the title "Effect of Smartphone Use on Changes in Student Behavior (Case Study of Senior High School Number 5 Palembang Students). Has a formulation of the problem of how the influence of smartphone usage on student behavior changes in senior high school 5 Palembang. The purpose of this study was to determine the effect of the use of smartphones on the change in student behavior in state high school number 5 Palembang. This research uses quantitative methods. The source of the data used is obtained through questionnaires, observations and interviews. And using data analysis techniques, namely descriptive analysis techniques and inferential analysis techniques. The theoretical framework used is the theory of Social Penetration. Based on the analysis of the data used and the simple Linear test, it was concluded that the use of smartphones has a very big influence on the changes in student behavior in senior high school number 5 Palembang. In this case it was also found that smartphone usage had a positive effect on changes in student behavior in senior high school number 5 Palembang.
\end{abstract}

Keywords: smartphone, interpersonal communication, behavior change.

\begin{abstract}
Abstrak
Era Teknologi dan Informasi yang saat ini serba praktis dan cepat tentu membuat banyak masyarakat untuk ingin mencoba ikut serta di dalam nya. Smartphone merupakan ponsel pintar yang berkembang hingga saat ini menjadi salah satu alat yang dapat digunakan banyak orang untuk bukan sekedar berkomunikasi, tetapi juga untuk menghibur diri, untuk mendapatkan informasi,


belajar hingga berkarya serta berjualan online. Smartphone yang semakin bertambahnya tahun, maka semakin berkembang pesat terkhusus kepada generasi milenial dan generasi $\mathrm{Z}$ saat ini dikhawatirkan dapat mempengaruhi perubahan perilaku nya sehari - hari. Smartphone yang menjadi kebutuhan ${ }^{\text {sehari }}$ - hari bagi para anak remaja tentu akan dilihat dari berbagai sisi, apakah berpengaruh besar positif negatif terhadap perilaku yang mereka terapkan sehari - hari. Banyaknya pengguna smartphone dari data - data yang telah ada menunjukkan besarnya antusias anak remaja untuk mengakses internet melalui smartphone. Penelitian ini dibuat dengan judul "Pengaruh Penggunaan Smartphone Terhadap Perubahan Perilaku Siswa (Studi Kasus Siswa Sekolah Menengah Atas Negeri 5 Palembang). Memiliki rumusan masalah bagaimana pengaruh penggunaan smartphone terhadap perubahan perilaku siswa di sekolah menengah atas negeri 5 Palembang. Tujuan penelitian ini adalah untuk mengetahui pengaruh penggunaan smartphone terhadap perubahan perilaku siswa di sekolah menengah atas negeri 5 Palembang. Penelitian ini menggunakan metode kuantitatif. Adapun sumber data yang digunakan didapatkan melalui kuesioner, observasi dan wawancara. Serta menggunakan teknis analisis data yaitu teknik analisis deskriptif dan teknik analisis inferensial. Kerangka teori yang digunakan adalah teori Penetrasi Sosial. Berdasarkan analisis data yang digunakan dan uji Linear Sederhana, maka diperoleh kesimpulan bahwa Penggunaan Smartphone berpengaruh sangat besar terhadap perubahan perilaku siswa di SMA Negeri 5 Palembang. Dalam hal ini juga ditemukan bahwa penggunaan smartphone berpengaruh positif terhadap perubahan perilaku siswa di SMA Negeri 5 Palembang.

Kata kunci : smartphone, komunikasi interpersonal, perubahan perilaku

\section{PENDAHULUAN}

Era Teknologi dan Komunikasi yang serba cepat dan praktis pada saat ini tentu membuat masyarakat berlomba - lomba ingin merasakan kecepatan serta kecanggihan daripada teknologi tersebut. Indonesia adalah salah satu pengguna terbesar alat teknologi dan komunikasi, Gadget merupakan satu dari sekian banyak nya. Gadget yang sangat begitu banyaknya ragam, dan smartphone adalah salah satunya. Dalam data yang diberitakan oleh detik.com mengatakan Negara Indonesia menjadi salah satu negara pengguna ponsel pintar aktif kelima dengan peringkat dibawah negara - negara asia seperti China, India, dan Jepang, serta negara Amerika dan Brazil.

Data dari detik.com dapat ditarik kesimpulan bahwa masyarakat Indonesia memiliki bagian besar dalam penggunaan ponsel pintar ini. Smartphone atau yang sering dikenal dengan ponsel pintar, selain menjadi gaya hidup baru bagi masyarakat khususnya siswa di sekolah, smartphone juga merupakan kebutuhan yang selalu melekat dalam kehidupan masyarakat, terkhusus pada generasi Y (Milenial) yang mampu untuk mengikuti kemajuan tekhnologi komunikasi.

Generasi $\mathrm{Y}$ atau yang biasa disebut dengan Generasi Mienial saat ini terbilang sering menggunakan sesuatu yang cepat atau instan seperti teknologi Informasi dan komunikasi contohnya email, SMS, dan media sosial. Generasi Y bercirikan bahwa setiap karakteristik individu 
berbeda tergantung dimana sosial keluarganya, strata ekonomi hingga ia dibesarkan. Pemakai sosial media yang bergantung dengan teknologi, berpengaruh besar dengan keadaan ekonomi serta politik. Pada akhirnya akan terlihat perubahan yang signifikan kepada lingkungan sekitar sehingga tertuju pada kekayaan. Dapat dipastikan bahwa media sosial menjadi suatu kewajiban bagi generasi Y saat ini.

Penggunaan Internet oleh generasi milenial sangat tinggi dibandingkan beberapa generasi sebelumnya (Ridwan, 2006). Komunikasi yang berjalan dengan baik dan efektif merupakan terdapatnya respon dari dua komunikan secara aktif. Komunikasi dalam kehidupan sehari - hari terdapat verbal maupun non verbal dengan konteks komunikasi interpersonal tentu dapat menjangkau apakah komunikasi tersebut dapat berjalan dengan baik. Komunikasi Interpersonal merupakan bagian besar dari komunikasi antar manusia. Sekitar 73\% komunikasi yang dilakukan manusia merupakan komunikasi interpersonal. Komunikasi yang terjalin secara interpersonal tentu lebih banyak digunakan oleh sebagian orang, karena keefektifan komunikasi tatap muka yang membuat individu tersebut dapat menyampaikan pesan secara tepat dan akurat. komunikasi interpersonal dapat menciptakan makna satu sama lain terhadap para komunikan. Pengelolaan hubungan serta proses pemaknaan mendapatkan timbal balik atau respon dari satu ke yang lain. Dengan besarnya fungsi dari Komunikasi interpersonal yang memiliki banyak manfaat seperti pembentukan karakter diri hingga penanganan suatu konflik yang terjadi didalam masyarakat. Perubahan sosial ialah berubahnya pola tertentu dalam kehidupan seseorang, sehingga menyebabkan berubahnya perilaku, baik ke arah positif maupun negatif, perubahan itu dapat terjadi dari dalam diri seseorang itu sendiri serta dapat terjadi karena dipengaruhi orang lain (luar) atau beberapa faktor lainnya (Budyatna, 2011).

Teori Penetrasi Sosial merupakan teori yang berhubungan kuat dengan perubahan perilaku suatu individu dengan individu yang lain dengan beberapa asumsi yang menjurus kepada suatu aspek yang mempengaruhi dan satu aspek yang dipengaruhi (Laurer, 2003), sehingga teori ini dapat dijadikan dasar dari penelitian yang menitikberatkan pengaruh penggunaan salah satu media baru terhadap perubahan perilaku dilkalangan siswa Sekolah Menengah Atas.

Banyaknya penggunaan Smartphone dikalangan remaja khususnya siswa sekolah menengah atas, tentu menjadi sebuah pertanyaan besar, apakah dengan adanya Smartphone yang menjadi ketergantungan hidup saat ini memiliki dampak terhadap perubahan perilaku siswa, khususnya siswa sekolah menengah atas negeri 5 Palembang, sebagai generasi milenial yang tentu sangat identik dengan alat pintar yang bernama "Smartphone". Penelitian ini mengkhususkan untuk mencari bagaimana dan apa saja perubahan perilaku yang terjadi dengan maraknya penggunaan smartphone pada siswa sekolah menengah atas di lingkungannya sehari - hari. Penelitian ini bukan mencari hubungan erat antara penggunaan smartphone terhadap prestasi akademik siswa, melainkan hubungan erat antara penggunaan smarphone terhadap perubahan perilaku nya didalam pergaulan sehari hari. 


\section{METODE PENELITIAN}

Metode Simple Correlation menjadi pegangan karena hanya memakai dan meneliti dua variabel yakni antara Pengaruh Penggunaan Smartphone serta Perubahan Perilaku Siswa. Sumber data dalam penelitian ini adalah primer. Data primer yaitu data yang diperoleh dari responden melalui kuesioner dan wawancara peneliti dengan narasumber. Data primer merupakan hasil pengisian kuisioner oleh responden yaitu Siswa kelas X dan XI Sekolah Menengah Atas Negeri 5 Palembang.

Jenis data yang digunakan dalam penelitian ini adalah jenis data kuantitatif yang diperoleh melalui kuesioner yang dibagikan kepada Siswa Sekolah Menengah Atas Negeri 5 Palembang sebagai Instrumen penelitian. Dalam penelitian ini data primer diperoleh dari kuesioner dan wawancara yang dilakukan pada sumber yang memiliki informasi mengenai hal-hal yang dibutuhkan dalam penelitian ini. Sedangkan data sekunder adalah data yang diperlukan untuk memperkuat hasil penelitian, dimana data tersebut sudah sebelumnya seperti dari buku atau literatur (Sugiono, 2009).

\section{HASIL DAN PEMBAHASAN}

Mengetahui pengaruh antara penggunaan Smartphone terhadap perubahan perilaku yang dirasakan oleh siswa Sekolah Menengah Atas Negeri 5 Palembang, merupakan tujuan dari penelitian ini. Untuk mencapai tujuan tersebut, maka diperlukan data-data yang menunjang seperti data primer. Peneliti memperoleh data primer melalui kuesioener yang berisikan pernyataan - pernyataan yang dijawab oleh responden

\section{Hasil Uji Validitas}

R Tabel : 0.256

\begin{tabular}{|c|c|c|c|c|}
\hline Variabel & $\begin{array}{c}\text { Nilai R } \\
\text { hitung }\end{array}$ & $\begin{array}{c}\text { Nilai R } \\
\text { tabel }\end{array}$ & $\begin{array}{c}\text { Nilai } \\
\text { Sig. }\end{array}$ & Keterangan \\
\hline Keterbukaan & 0.906 & 0.256 & 0.05 & Valid \\
\hline Empati & 0.971 & 0.256 & 0.05 & Valid \\
\hline Sikap Mendukung & 0.695 & 0.256 & 0.05 & Valid \\
\hline Kesamaan & 0.921 & 0.256 & 0.05 & Valid \\
\hline Sikap Positif & 0.951 & 0.256 & 0.05 & Valid \\
\hline Perubahan Perilaku & 1.0 & 0.256 & 0.05 & Valid \\
\hline
\end{tabular}

Sumber : Pengolahan Data menggunakan SPSS 25.0

Hasil uji validitas di tabel di atas menunjukkan bahwa semua variabel yaitu Keterbukaan, Empati, Sikap Mendukung, Kesamaan, Sikap Positif, dan Perubahan Perilaku Siswa mendapatkan 
hasil valid, kesimpulan ini diambil dari $r$ hitung $\geq r$ tabel (uji 2 sisi dengan sig. 0,01) maka nilai hasil dapat dinyatakan valid.

Hasil Uji Reliabilitas

\begin{tabular}{|c|c|c|c|c|}
\hline No & Variabel & $\begin{array}{c}\text { hasil } \\
\text { Alpha } \\
\text { Cronbach }\end{array}$ & $\begin{array}{c}\text { Standar } \\
\text { Cronbach } \\
\text { Alpha }\end{array}$ & keterangan \\
\hline 1 & Keterbukaan & 0.654 & 0,600 & reliabel \\
\hline 2 & Empati & 0.714 & 0,600 & reliabel \\
\hline 3 & Sikap Mendukung & 0.663 & 0,600 & reliabel \\
\hline 4 & Kesamaan & 0.746 & 0,600 & reliabel \\
\hline 5 & Sikap Positif & 0.761 & 0,600 & reliabel \\
\hline 6 & Perubahan Perilaku & 0.694 & 0,600 & reliabel \\
\hline
\end{tabular}

Sumber : Pengolahan data menggunakan SPSS 25.0

Berdasarkan hasil uji reliabilitas di tabel di atas menunjukkan bahwa semua variabel yaitu Keterbukaan, Empati, Sikap Mendukung, Kesamaan, Sikap Positif, dan Perubahan Perilaku Siswa mendapatkan hasil yang reliabel, kesimpulan ini terlihat dari nilai Cronbach alpha yang lebih besar dari 0,600. Kesimpulannya adalah, kuesioner telah dinyatakan valid dan reliabel, maka kuesioner tersebut sudah dapat dan layak diberikan serta sebarkan kepada responden untuk mengadakan penelitian.

\section{Variabel Penggunaan Smartphone}

Smartphone merupakan ponsel pintar yang dapat mengakses berbagai layanan internet, aplikasi serta media mendapatkan informasi yang sering digunakan oleh siswa siswi kelas X dan XI di Sekolah Menengah Atas Negeri 5 Palembang.

\section{Sub Variabel Keterbukaan}

$57.6 \%$ dari total responden menyatakan sering terhadap pernyataan informasi diri yang disampaikan berupa kebohongan. 54.2\% menyatakan sering terhadap penyataan menerima masukan dari orang lain melalui media publik. $44.1 \%$ orang menyatakan kadang - kadang terhadap pernyataan menutup diri dari publik akan informasi diri yang privasi. $42.4 \%$ responden menyatakan kadang - kadang terhadap pernyataan nilai kejujuran menyampaikan informasi dan citra diri. $39.0 \%$ menyatakan jarang terhadap pernyataan tidak suka menerima masukan dari orang lain melalui media publik. 


\section{Sub Variabel Empati}

Pernyataan "Mampu memahami perasaan dan pendapat orang lain" adalah sebanyak $44.1 \%$ menjawab sering. Menyatakan sering terhadap pernyataan "Saran, kritik, dan masukan dari orang lain tidak lah penting" sebanyak $57.6 \%$ responden, Menyatakan sering terhadap pernyataan "Perasaan dan pendapat orang lain sulit difahami" yaitu sebesar 54.2\%, pernyataan kadang kadang terhadap pernyataan "Keterbukaan dalam menerima saran, kritik, dan masukan" sebanyak $42.4 \%$ responden.

\section{Sub Variabel Sikap Mendukung}

Responden menyatakan sering terhadap pernyataan "Mendahulukan kepentingan kelompok dari kepentingan pribadi" sebanyak $44.1 \%$, responden menyatakan jarang terhadap pernyataan "Komunikasi terjalin dua arah" sebanyak 33.9\%, responden menyatakan tidak pernah terhadap pernyataan "Kepentingan pribadi lebih utama daripada kepentingan kelompok" sebanyak $30.5 \%$, responden menyatakan kadang-kadang terhadap pernyataan "Tidak merespon perkataan teman ketika bermain smartphone" sebanyak $42.4 \%$, responden menyatakan sering terhadap pernyataan "Saling memerlukan orang lain" sebanyak $49.2 \%$, responden yang menyatakan kadang-kadang sebanyak $32.2 \%$, yang menyatakan sangat sering sebanyak $11.9 \%$ responden, yang menyatakan jarang dan tidak pernah sebanyak $3.4 \%$ responden. responden menyatakan sering terhadap pernyataan "Keakraban komunikasi sehingga akrab dan nyaman" sebanyak $57.6 \%$, responden menyatakan sering terhadap pernyataan "Timbul rasa resah dan gelisah sehingga tidak akrab berkomunikasi” sebanyak $54.2 \%$, responden yang menyatakan kadang-kadang sebanyak $28.8 \%$, yang menyatakan sangat sering sebanyak $10.2 \%$ responden, yang menyatakan jarang dan tidak pernah sebanyak $3.4 \%$ responden. responden menyatakan kadang-kadang terhadap pernyataan "Tidak memerlukan orang lain" sebanyak $44.1 \%$.

\section{Sub Variabel Sikap Positif}

Responden menyatakan sering terhadap pernyataan "Memberikan fikiran positif terhadap orang lain" sebanyak $44.1 \%$, responden menyatakan sering terhadap pernyataan "Acuh dan tidak memerlukan bantuan orang lain" sebanyak $57.6 \%$, responden menyatakan sering terhadap pernyataan "Kepercayaan akan membutuhkan orang lain" sebanyak $54.2 \%$, responden menyatakan kadang - kadang terhadap pernyataan "selalu berfikir negatif kepada orang lain" sebanyak $42.4 \%$.

\section{Perubahan Perilaku Siswa}

$57.6 \%$ menyatakan setuju terhadap pernyataan "Komunikasi menjadi antusias dan saling membuka diri satu dengan yang lain dengan adanya smartphone", kemudian responden menyatakan sangat setuju terhadap pernyataan tersebut yakni $10.2 \%$. Responden menyatakan setuju terhadap pernyataan "Hubungan menjad intim dan dalam sehingga menjadi lebih luas dengan adanya smartphone" yakni $54.2 \%$ dan responden yang menyatakan sangat setuju terhadap pernyataan 
tersebut yakni $10.2 \%$. Responden menyatakan kurang setuju terhadap pernyataan "Hubungan tidak berjalan lancar dan memudar sehingga menjauhkan secara bertahap" yakni $44.1 \%$, responden yang menyatakan tidak setuju terhadap pernyataan tersebut yakni $15.3 \%$, dan responden yang menyatakan sangat tidak setuju terhadap pernyataan tersebut yakni $11.9 \%$ responden.

\section{Analisis Statistik Inferensial}

Setelah dilakukan analisis deskriptif, maka untuk mengetahui adanya korelasi antara variabel penelitian, perlu dilakukan analisis statistic inferensial untuk menguji hipotesis, baik hipotesis mayor maupun hipotesis minor yang telah diajukan penelitian: "PENGARUH PENGGUNAAN SMARTPHONE TERHADAP PERUBAHAN PERILAKU SISWA (Studi Kasus Siswa Sekolah Menengah Atas Negeri 5 Palembang).

Data serta informasi telah didapatkan selama proses penelitian melalui pengumpulan data dan pengolahan awal adalah dasar pengujian hipotesis dan penarikan kesimpulan. Dalam pengujian yang dimaksud, penulis menggunakan korelasi Rank Spearman dengan alasan jenis korelasi inilah yang tepat digunakan pada data yang berskala ukur ordinal. Tingkat signifkan yang dipilih dalam pengujian hipotesis penelitian kali ini adalah $\alpha=0,05$.

\section{Pengaruh Penggunaan Smartphone Terhadap Perubahan Perilaku Siswa}

Analisis hipotesis mayor yaitu menganalisis hubungan variabel $\mathrm{X}$ dengan variabel $\mathrm{Y}$, yaitu hubungan Penggunaan Smartphone dan Perubahan perilaku siswa.

\section{Korelasi Mayor}

\begin{tabular}{|c|c|c|c|}
\hline & & $\begin{array}{l}\text { Penggunaan } \\
\text { Smartphone }\end{array}$ & $\begin{array}{c}\text { Perubahan } \\
\text { Perilaku }\end{array}$ \\
\hline \multirow{4}{*}{$\begin{array}{l}\text { Penggunaan } \\
\text { Smartphone }\end{array}$} & Pearson & 1 & $949^{* * *}$ \\
\hline & Correlation & & \\
\hline & Sig. (2-tailed) & &, 000 \\
\hline & $\mathrm{N}$ & 59 & 59 \\
\hline \multirow[t]{4}{*}{ Perubahan Perilaku } & Pearson &, $949^{* *}$ & 1 \\
\hline & Correlation & & \\
\hline & Sig. (2-tailed) & 000 & \\
\hline & $\mathrm{N}$ & 59 & 59 \\
\hline
\end{tabular}


**. Correlation is significant at the 0.01 level (2-tailed).

Sumber : Pengolahan data menggunakan SPSS 25.0

\section{Analisis Hipotesis Minor}

Jika pada sebelumnya dicari analisis korelasional secara umum antara variabel Penggunaan Smartphone dengan Perubahan Perilaku Siswa, maka dibawah ini akan diberikan sub variabel dari kedua variabel tersebut / hipotesis mayor.

\section{Correlations}

\section{Korelasi Minor}

\begin{tabular}{|c|c|c|c|c|c|c|c|}
\hline \multicolumn{8}{|c|}{ Correlations } \\
\hline & & keterbukaan & empati & $\begin{array}{c}\text { sikap } \\
\text { mendukung }\end{array}$ & kesamaan & sikap positif & $\begin{array}{c}\text { perubahan } \\
\text { perilaku }\end{array}$ \\
\hline \multirow[t]{3}{*}{ keterbukaan } & Pearson Correlation & 1 & $882^{\star \pi}$ &, $579^{\star \pi}$ & $808^{\star \pi}$ & $866^{\pi \star}$ & $906^{\star \star}$ \\
\hline & Sig. (2-tailed) & &, 000 &, 000 &, 000 &, 000 &, 000 \\
\hline & $N$ & 59 & 59 & 59 & 59 & 59 & 59 \\
\hline \multirow[t]{3}{*}{ empati } & Pearson Correlation &, $882^{\star \pi}$ & 1 &, $722^{\pi x}$ & $927^{\star \pi}$ & $997^{\star \star}$ & $971^{\pi \times}$ \\
\hline & Sig. (2-tailed) &, 000 & &, 000 &, 000 &, 000 &, 000 \\
\hline & $\mathrm{N}$ & 59 & 59 & 59 & 59 & 59 & 59 \\
\hline \multirow[t]{3}{*}{ sikap mendukung } & Pearson Correlation &, $579^{\star \pi}$ &, $722^{\star \star}$ & 1 & $858^{\star \star}$ &, $725^{\star \star}$ & $694^{\star \star}$ \\
\hline & Sig. (2-tailed) &, 000 &, 000 & &, 000 &, 000 &, 000 \\
\hline & $\mathrm{N}$ & 59 & 59 & 59 & 59 & 59 & 59 \\
\hline \multirow[t]{3}{*}{ kesamaan } & Pearson Correlation &, $808^{\star \pi}$ & $927^{\star \star}$ & $858^{\star \pi}$ & 1 & $919^{\star x}$ & $921^{\star \star}$ \\
\hline & Sig. (2-tailed) &, 000 &, 000 &, 000 & &, 000 &, 000 \\
\hline & $N$ & 59 & 59 & 59 & 59 & 59 & 59 \\
\hline \multirow[t]{3}{*}{ sikap positif } & Pearson Correlation & $866^{\star \star}$ & $997^{\star \star}$ &, $725^{\star \pi}$ & $919^{\star \pi}$ & 1 &, $951^{\star \star}$ \\
\hline & Sig. (2-tailed) &, 000 &, 000 &, 000 &, 000 & &, 000 \\
\hline & $N$ & 59 & 59 & 59 & 59 & 59 & 59 \\
\hline \multirow[t]{3}{*}{ perubahan perilaku } & Pearson Correlation & $906^{\star \pi}$ & $971^{\star \star}$ &, $694^{\star \pi}$ &, $921^{\star \pi}$ & $951^{\pi \star}$ & 1 \\
\hline & Sig. (2-tailed) &, 000 &, 000 &, 000 &, 000 &, 000 & \\
\hline & $N$ & 59 & 59 & 59 & 59 & 59 & 59 \\
\hline
\end{tabular}

Sumber : Pengolahan data menggunakan SPSS 25.0

Pengujian hipotesis dilakukan dengan teknik analisis korelasi sederhana antara $\mathrm{X}$ dengan $\mathrm{Y}$ menghasilkan koefisien korelasi (r) sebesar 0.949 (lihat tabel 3.16) dari tabel tersebut diatas bahwa nilai sig. (1-tailed) sebesar 0.000 lebih kecil dari $\alpha=0,05$ artinya berkorelasi. Dan koefisien korelasi (r) sebesar 0.949 korelasi sempurna. 


\title{
Pengujian Kriteria Normalitas Instrumen Penelitian
}

\author{
Hasil Uji Normalitas
}

\section{One-Sample Kolmogorov-Smirnov Test}

\begin{tabular}{llr} 
& & $\begin{array}{r}\text { Unstandardiz } \\
\text { ed Residual }\end{array}$ \\
\hline $\mathrm{N}$ & & 59 \\
\hline Normal Parameters $^{\mathrm{a}, \mathrm{b}}$ & Mean &, 0118644 \\
\cline { 2 - 3 } & $\begin{array}{l}\text { Std. } \\
\text { Deviation }\end{array}$ &, 80610810 \\
\hline Most Extreme & Absolute &, 119 \\
\cline { 2 - 3 } Differences & Positive &, 119 \\
\cline { 2 - 3 } & Negative &,- 073 \\
\hline Test Statistic & &, 119 \\
\hline Asymp. Sig. (2-tailed) & &, $036^{c}$ \\
\hline a. Test distribution is Normal. & \\
b. Calculated from data. & \\
\hline c. Lilliefors Significance Correction. &
\end{tabular}

Sumber : Pengolahan data menggunakan SPSS 25.0

Berdasarkan hasil uji normalitas di tabel 3.18 menunjukkan bahwa nilai signifikansi $\mathbf{0 . 0 3 6}$ > 0.05. maka dapat disimpulkan bahwa nilai residual berdistribusi normal.

\section{Pengujian Kriteria Linearitas Instrumen Penelitian}

\section{Hasil Uji Linearitas}

\begin{tabular}{|c|c|c|c|c|c|c|c|}
\hline \multicolumn{8}{|c|}{ ANOVA Table } \\
\hline & & & $\begin{array}{l}\text { Sum of } \\
\text { Squares }\end{array}$ & df & Mean Square & $\mathrm{F}$ & Sig. \\
\hline \multirow{5}{*}{$\begin{array}{l}\text { Perubahan Perilaku * } \\
\text { Penggunaan } \\
\text { Smartphone }\end{array}$} & \multirow[t]{3}{*}{ Between Groups } & (Combined) & 331,223 & 39 & 8,493 & 3,495 &, 002 \\
\hline & & Linearity & 300,478 & 1 & 300,478 & 123,662 &, 000 \\
\hline & & Deviation from Linearity & 30,745 & 38 &, 809 &, 333 & ,998 \\
\hline & Within Groups & & 46,167 & 19 & 2,430 & & \\
\hline & Total & & 377,390 & 58 & & & \\
\hline
\end{tabular}


Sumber : Pengolahan data menggunakan SPSS 25.0

Berdasarkan hasil uji linearitas di tabel 3.19 menunjukkan bahwa nilai sig. Deviation from Linearity sebesar $0.998>0.05$. maka dapat disimpulkan bahwa terdapat hubungan yang linear antara Penggunaan Smartphone dan Perubahan perilaku siswa.

\section{Analisis Regresi Linear Sederhana (Simple Linear Regression)}

\section{Hasil Uji Regresi Linear Sederhana}

\section{Ringkasan Model}

\section{Model Summary}

\begin{tabular}{rr|r|r|r} 
Model & $\mathrm{R}$ & R Square & \multicolumn{1}{|c}{$\begin{array}{c}\text { Adjusted R } \\
\text { Square }\end{array}$} & $\begin{array}{l}\text { Std. Error of } \\
\text { the Estimate }\end{array}$ \\
\hline 1 &, $892^{\mathrm{a}}$ &, 796 &, 793 & 1,16161 \\
\hline
\end{tabular}

a. Predictors: (Constant), Penggunaan Smartphone

b. Dependent Variable: Perubahan Perilaku

Sumber : Pengolahan data menggunakan SPSS 25.0

Berdasarkan hasil uji regresi linear sederhana ringkasan model di tabel 3.21 menunjukkan bahwa nilai koefisien determinasi ( $R$ Square) sebesar $\mathbf{0 . 7 9 6}$ yang mengandung pengertian bahwa pengaruh variabel bebas (penggunaan smartphone) terhadap variabel terikat (perubahan perilaku) adalah sebesar $\mathbf{7 9 . 6 \%}$

\section{Hasil Uji Regresi Linear Sederhana \\ Analysis of variance (ANOVA)}

\begin{tabular}{|c|c|c|c|c|c|c|c|}
\hline \multicolumn{8}{|c|}{ ANOVA Table } \\
\hline & & & $\begin{array}{l}\text { Sum of } \\
\text { Squares }\end{array}$ & df & Mean Square & $\mathrm{F}$ & Sig. \\
\hline \multirow{2}{*}{$\begin{array}{l}\text { Perubahan Perilaku * } \\
\text { Penggunaan } \\
\text { Smartphone }\end{array}$} & \multirow[t]{2}{*}{ Between Groups } & (Combined) & 331,223 & 39 & 8,493 & 3,495 & 002 \\
\hline & & Linearity & 300,478 & 1 & 300,478 & 123,662 &, 000 \\
\hline \multicolumn{4}{|c|}{ Sumber : Pengolahan data mengtion frnakinearisPSS $25^{30} .0^{45}$} & 38 & 809 &, 333 & ,998 \\
\hline & \multicolumn{2}{|c|}{ Within Groups } & 46,167 & 19 & 2,430 & & \\
\hline & \multicolumn{2}{|l|}{ Total } & 377,390 & 58 & & & \\
\hline
\end{tabular}


Berdasarkan hasil uji regresi linear sederhana ANOVA di tabel 3.22 menunjukkan bahwa nilai $\mathrm{F}_{\text {hitung }}$ sebesar 123.662 dengan tingkat signifikansi sebesar $0.000<0.05$ yang mengandung pengertian bahwa ada pengaruh variabel bebas (penggunaan smartphone) terhadap variabel terikat (perubahan perilaku).

\section{Hasil Uji Regresi Linear Sederhana coefficients}

\begin{tabular}{|c|c|c|c|c|c|c|}
\hline \multicolumn{7}{|c|}{ Coefficients $^{\mathrm{a}}$} \\
\hline & & \multicolumn{2}{|c|}{$\begin{array}{c}\text { Unstandardized } \\
\text { Coefficients }\end{array}$} & \multirow{2}{*}{$\begin{array}{c}\text { Standardized } \\
\text { Coefficients } \\
\text { Beta }\end{array}$} & \multirow[b]{2}{*}{$\mathrm{T}$} & \multirow[b]{2}{*}{ Sig. } \\
\hline \multicolumn{2}{|c|}{ Model } & B & Std. Error & & & \\
\hline \multirow[t]{2}{*}{$\overline{1}$} & (Constant) & ,956 & ,880 & & 1,086 &, 282 \\
\hline & Penggunaan Smartphone & , 143 & 010 & ,892 & 14,923 &, 000 \\
\hline
\end{tabular}

a. Dependent Variable: Perubahan Perilaku

Sumber : Pengolahan data menggunakan SPSS 25.0

Berdasarkan hasil uji regresi linear sederhana coefficients di tabel 3.23 menunjukkan bahwa nilai constant (a) sebesar $\mathbf{0 . 9 5 6}$, sedangkan nilai penggunaan smartphone (b / koefisien regresi) sebesar 0.143. sehingga persamaan regresi nya :

$$
\begin{aligned}
& Y=a+b X \\
& Y=0.956+0.143 X
\end{aligned}
$$

Konsisten variabel partisipasi adalah sebesar 0.956

Koefisien regresi $X$ sebesar $\mathbf{0 . 1 4 3}$ menyatakan bahwa setiap penambahan $1 \%$ nilai penggunaan smartphone, maka nilai partisipasi bertambah 0.14. Koefisien regresi tersebut bernilai positif, sehingga dapat dikatakan bahwa arah pengaruh variabel $\mathrm{X}$ terhadap variabel $\mathrm{Y}$ adalah positif. Berdasarkan hasil uji regresi linear sederhana coefficients di tabel 3.23 menunjukkan bahwa :

- Berdasarkan nilai signifikansi : nilai signifikansi sebesar $\mathbf{0 . 0 0 0}<\mathbf{0 . 0 5}$ sehingga dapat disimpulkan bahwa variabel penggunaan smartphone $(\mathrm{X})$ berpengaruh terhadap variabel perubahan perilaku siswa (Y)

- Berdasarkan nilai $\mathrm{t}$ : nilai $\mathrm{t}$ hitung sebesar $\mathbf{1 4 . 9 2 3}>\mathrm{t}$ tabel $\mathbf{1 . 6 2 7}$ sehingga dapat disimpulkan bahwa variabel penggunaan smartphone $(\mathrm{X})$ Berpengaruh terhadap variabel perubahan perilaku siswa (Y).

\section{KESIMPULAN}

Hasil analisis data dan hasil daripada penelitian ini, dapat diambil kesimpulan mengenai pengaruh penggunaan smartphone terhadap perubahan perilaku siswa (studi kasus siswa sekolah menengah atas negeri 5 Palembang) yakni :

Hasil analisis linear sederhana, diperoleh $\mathrm{Y}=0.956+0.143 \mathrm{X}$, dengan variabel $\mathrm{X}$ yang terdiri 
dari keterbukaan, empati, sikap mendukung, kesamaan, dan sikap positif terhadap variabel $\mathrm{Y}$ yakni perubahan perilaku. selanjutnya hasil $t$ hitung diperoleh sebesar 14.923 sedangkan $t$ tabel didapatkan nilai sebesar 1.627. maka dari itu $t$ hitung $>t$ tabel, nilai $t$ hitung lebih besar dari jumlah $t$ tabel. Dapat disimpulkan H0 ditolak dan H1 diterima yang berarti terdapat pengaruh besar Penggunaan Smartphone terhadap Perubahan Perilaku Siswa.

Melalui ringkasan model dalam analisis linear sederhana, nilai koefisien determinasi $(R$ Square) sebesar 0.79 yang mengandung pengertian bahwa pengaruh penggunaan smartphone terhadap perubahan perilaku siswa sebesar 79\%. Berdasarkan hasil uji linear sederhana coefficients menunjukkan bahwa nilai koefisien regresi penggunaan smartphone sebesar 0.143 yang bernilai positif, sehingga dapat disimpulkan arah pengaruh penggunaan smartphone terhadap perubahan perilaku siswa adalah pengaruh positif. 


\section{DAFTAR PUSTAKA}

Akdon, Ridwan. (2006). Aplikasi Statistika dan Metode Penelitian Untuk Administrasi dan Manajemen Bandung, Dewa Ruci

Ali, Hasan. (2008). Marketing (Yogyakarta, Media Pressindo

Ali, M. (1987). Guru dalam Proses Belajar Mengajar, Bandung : P.T. Sinar Baru

Ardianto dkk. (2004). Komunikasi Massa Suatu Pengantar, Bandung: Remaja Rosdakarya

Azwar, Saifuddin. (1986). Realibilitas dan Validitas : Interprestasi dan Komputasi, Yogyakarta, Liberti

Azwar, Saifuddin. (1998). Sikap manusia, Teori, dan Pengukurannya, Yogyakarta : Pustaka Pelajar.

Budyatna, Muhammad, Leila. (2011). teori komunikasi antarpribadi, Jakarta: Kencana

Bungin, Burhan. (2001). Metodologi Penelitian Kualitatif. Jakarta: PT Raja Grafindo Persada.

Cholid, Narbuko dan Abu Achmadi. (2002). Metodologi Penelitian, Jakarta: PT. Bumi Aksar

Danim, Sudarwan. (2012). Motivasi Kepemimpinan dan Efektivitas Kelompok, Jakarta : Rineka Cipta

Dayakisni, Tri \& Hudainah. (2009). Psikologi Sosial, Malang: UMM Press

Donald R. Cooper \& Pamela S.Schindler. (2006). Bussines Research Metodhs, Mc-Education (New York: Mc Graw -Hill Companies, Inc. 2008)

Ghozali, Imam. (2009). Aplikasi Analisis Multivariate Dengan Program SPSS Edisi Keempat, Semarang: Badan Penerbit Universitas Diponegoro

Graw Hill International Edition

H. Laurer, Robert. (2003). Perspektif Tentang Perubahan Sosial, (Jakarta : Rineka Cipta

Soekanto, Soerjono. (2010). Sosiologi Suatu Pengantar edisi ke- 43, Jakarta : PT. Raja Grafindo, Sugiono. (2009). Metode Penelitian Kuantitatif, Kualitatif dan R\&D, (Bandung, Alfabeta, Sugiono. (2009). Metode Penelitian Pendidikan, Bandung: Alfabeta

Sunyoto, Danang. (2007). Analisis Regresi dan Korelasi Bivariat Ringkasan dan Kasus, Yogyakarta: Amara Books

Suranto. (2011). Komunikasi Interpersonal, Yogyakarta : Graha Ilmu

Walgito, Bimo. (2003). Psikologi Sosial Suatu Pengantar, Yogjakarta : Andi

Zein, Zetty dkk. (2005). Psikologi Ibu dan Anak, Yogyakarta: Fitramaya 